ARTIGO

Recebido em: 29/05/2014

Aceito em: $05 / 07 / 2014$

\title{
Using networks in patent exploration: application in patent analysis: the democratization of 3D printing
}

David REYMOND 1

Jessica DEMATRAZ2

\begin{abstract}
Bibliometry coupling is used to process bibliographic data to assert existing latent information on publication material. We apply here this technique on patent data gathered from the OPS web service to enhance the exploration process of patents using network visualization. The following will present briefly graph theory preliminaries, the gathering and transforming process on the ops base. The different networks produced will be discussed and placed in a generic economic intelligence process. Finally we present a case study using this approach to discuss the democratization of 3D printing.
\end{abstract}

KEYWORDS: Social network analysis. Scientometrics. Collaboration.

\footnotetext{
1 Université Nice Sophia Antipolis, Nice, France et Université de Toulon, La Garde, France david.reymond@univ-tln.fr

2 Université de Toulon - jessica.dematraz@gmail.com
} 


\section{INTRODUCTION}

The Competitive Intelligence (CI) is a monitoring process that integrates relevant and useful information to all decision making. This process is generally operated with external organizations and the Internet has shown, since his accession as an excellent informational source. Recently, open data and "Big Data" flow to the exponential growth of network data which contributes to further enrich this informational source of interest to the CI. The volume and dynamics of the network then impose the implementation of the necessaries tools [10] that becomes of fundamental interest to the IC. This is particular the case of the European Patent Office (EPO) online database. While "patents are used by countries as a tool for competitiveness" (Pascal Grivet) the EPO web interface (http://www.epo.org/ [xiii]) now offers access to approximately 80 million patents. These patents, written in the language of the country of posting, are described and classified by so-called "bibliographic data". This database is part of the invisible web as only the web form or the API allows access to patent data. The interface provides simple to complex query forms. It is however the features in the API (Application Programming Interface) that releases the entire basis for automated queries. Thus, the Open Patent Services Erro! Fonte de referência não encontrada. provides access to a global patent database, built by aggregation of different national bases (90 countries). We will show and discuss the PatentToNet suite as a part of a dynamic movement of the IC [42] coupling automated data collection, sorting and selection [53][33], visualization [52] and navigation for exploration [43].

The first part of this article we will briefly present graph theory concept and the necessary vocabulary to understand the following. We then outline the basic principles of a gathering function sending a request (set of keywords and connectors) determined by the "watchman" to the OPS web service. The function will provide descriptive data (bibliographic data) of the patents it identifies. The watchman should correctly choose their keywords for this set to define and identify a particular concept, an input for its standby patent issue. The tools developed will enable the watchman to get rid of the technical aspects to focus on the interpretation and communication of data processed only to 
clients that are CI makers.

The second part will discuss the arrangements and crossings of the data collected for the development of informational constructed from bibliographic patent data extracted networks. For example, the inventors and their coworking relationships associated with the patents that may be seen as "expert networks" around a concept. Or the holders of patents that are corporate networks, and so on.

The search result on a keyword can produce very large sets of data (one hundred to several thousands of patents). Therefore, all previously produced knowledge (networks of inventors, companies holding patents networks...) requires the use of visualization tools [53] and a suitable navigation system for complex data. It requires also enabling the segmentation of the data according to specific criteria, calculating the topology of their arrangement (extracted as patent scope, nationality, classification eg. properties). It must be able to show related sets around a concept, such as to nearby businesses sharing inventors or those sharing patents. This reorganization of data is produced by the visualization algorithms which coupled navigation tools to allow the emergence of latent properties of collected data [17]. The use of these tools allows the watcher to understand more easily the complex data. Thus, by formatting EPO extractions into graphs file, we open through the traditional tools of the field, a path to intelligence facilitated on an overview of previously inaccessible data, which diminish the search time required for its apprehension.

\section{NETWORK PRELIMINARIES}

Roads, wires, communities we are all rounded by networks as said Musso. Graph theory as a branch of mathematics dates back to Euler (1736). Since, a lot of development have been done many thanks to its usage in sociology with the development of sociometry (Parlebas, 1992) : Graph theory provides [...] an arsenal of concepts, theorems, algorithms and reasoning conducive to network analysis, and through which the graphic representation beyond mere representation to allow a mathematical treatment generating new 


\section{knowledge.}

Computer scientists have developed powerful algorithms that allow the characterizations of network in a reasonable time providing tools to describe and characterize such structures. They also developed programs to visualize and permit the representation of huge structures, adding properties and allowing the user to manipulate and explore their content.

There are several assertions or contexts of meaning of the concept of network. [2] enumerates four of them:

- A systemic version the network will represent the functional exchange of individual and institutional actors with common or complementary objectives and connoting both a descriptive meaning and normative sense

- a socio-technologically updated version refers to new forms of organization that arise and evolve, usually associated with the development of certain technologies;

- an economy version, in which the concept of network is part of the innovation theory, or more precisely, the theory of social systems of innovation;

- Finally, a increasing capacity version as an organizational form that achieves critical mass in distributed system.

These varied considerations allow us to underline the necessity of determining a priori objects and relationships between these objects that will be represented by a graph. The semantics of this representation, i.e. the combination of arcs or edges to a notion of special relationship (citation, economic link, privileged relationship, etc.) will influence the scope of the features that will be revealed in the processing and, of course determinate the way of possible interpretations. 


\subsection{Basic definitions and vocabulary}

A graph is composed of units called nodes or vertices and relationships of a particular type between them, called edges or lines). In the case where the edges are marked by a direction between the vertices they connect, the graph is directed and called a directed graph or digraph. The edges are, in this case, called arcs.

Nodes may represent people, a router, a website, a html document; etc.The edges can represent knowledge like links between people, network wires, connections to and from other sites, hyperlinks in the document, or those pointing to that document, etc. The first two examples give simple graphs (vertices, edges), while the second will be directed graphs (vertices, arcs).

We invite the reader to consult Degenne and Forsé [12] for a more precise introduction to networks.

\subsection{Characterizations}

From these preliminary definitions, one can discuss several proprieties of graph in which some applies globally on the whole structure and others locally to each node. We remind hereafter the main ones.

\subsubsection{Global metrics}

The whole graph can be characterized by its density, i.e. counting the number of links (undirected) of a graph compared to a complete graph (in which all nodes are relied to others) of the same order (number of nodes). The number of links of a complete network counting $\mathrm{N}$ nodes is $\mathrm{N} .(\mathrm{N}-1)$ links. Density information is valuable to appreciate the capacity of flowing information within a network.

The second main characteristic for describing the whole graph is the paths within it, which is the suite of nodes one can use for going from one node to other. This characteristic is immediately relied to Moreno's chains [38], the fundamental sociometrics. 


\subsubsection{Local metrics}

The degree of a node is the number of edges of the node. In a digraph, one can distinguish in-links (In-degree) and outlinks (outdegree). Then, a node can be [51]:

- Isolated if there no links from or to it,

- Transmitter, if it receives no links (Indegree $=0$ ) and at send one outdegree $>0$,

- Receiver if it sends no links (Outdegree $=0$ ) and receive at least one indegree $>0$,

- Carrier, if at least it receives one links and sends at least one.

These nodes characteristics are useful to discuss singular connectivity, but one may need also to discuss its centrality in a graph, well known notion in Social Network Analysis (SNA).

\subsubsection{Centrality}

Centrality is a measure of how many connections one node has to other nodes. There are four main centrality measures in network theory. Aside the calculus of node proximity relatively to other, one can express different form of proximity [21]:

- Degree centrality is the number of connections to other nodes: nodes that have more links may have multiple alternative ways and resources to reach other;

- Closeness centrality is the average distance from each node to every other node in the network. High closeness centrality nodes are called influencers within their local network community and are near the center of local clusters,

- Betweeness centrality shows the capability of a node to delivers flow to all others but also the necessary nodes that must be traversed to go from one part of the network to other. High betweenness nodes often do not have the shortest average path to every node, but they have the greatest number of shortest paths that necessarily have to go through them. 
- Eigenvector centrality, expressed the effective connection to wellconnected nodes in the network. High eigenvector centrality nodes are also called "leaders" of the network.

Advances in measurement have been regular SNA and many others measures exist beyond the scope of our purpose such as, for instance, Hubbell, and Katz, Taylor, Stephenson, and Zelen measures [51].

\subsection{Network clustering}

Clustering is the unsupervised classification of patterns [29] (observations, data items, or feature vectors) into groups (clusters)[28][23]. In network analysis, clustering algorithm provides the way to subnet the whole network into partitions, pairing nodes into communities groups [7] in the SNA context.

\subsection{Graph visualization}

The use of visual images is common in many branches of science. Alfred Crosby (1997) has proposed that visualization in complement of measurement is responsible for the explosive development of all of modern science [18]. Visualization is seen as a material to understand the complexity of network [20]. Exploration of spatial representations goes further these ideas and is needed in the case of a complex dataset such as network can be [48] where the complexity challenges the art of representation [11].

There is a huge literature on network visualization [15][16][24]. Between the many existing layouts, the following have retained our attention, most of them are actually implemented in the network visualization tool we use [4]:

- Showing divisions: Openord [36]

- Complementarity enhancing: Force Atlas[4], Frushterman, Reingold [22], Yifan Hu [26]

- Showing classification: Circular, Radial axis [8][27]

- Geographic repartition: Geographic Layout [5][38], 
- Describing connections (undirected graphs): Kamada-Kawaï [30][31]

The interested reader is referred to [11][33] for a deeper insight and many more sophisticated data visualization methods.

From there we propose the use of graph theory toolkit in the informational process in the Competitive Intelligence flow applied to patent analysis and present first the data gathering and treatments processes.

\section{OPS BASE AND GATHERING PROCESS TOOL}

Patent2 $\mathrm{Net}^{3}$ is a python script suite written in Cecil-B Licence 4 (GNU GPL under French laws) that provides the following:

- OPSGather-PatentList: send a request to the OPS base API and writes the patent list received from this request. The request will follow the OPS Smart Search format and allows very complex requests. A filename placed as the first parameter of the script is used to write the patent list.

- OPSGather-BiblioPatents: aimed to use the previous file, the script will collect a bunch of bibliometric data according to the patent list (filename parameter). For each patent the script will gather: Inventors, Applicants, date of deposit, Country, Classification and Kind.

- OPSGather-Claims also use the file produced by OPSGather-PatentList to gather Claims associated to each patent. Actually in beta version.

- PatentToNet aims to produce the network of patents associated to the request into gexf format with useful attributes to their manipulation, exploration and understanding trough Gephi.

For each Patent in the list, a node is created. The year of this patent, the category (Patent) and the direct url to its description in the OPS website are specified as attributes. Nodes for each bibliometric data already present in the network are created and linked from patent Node. Hence, in the network

\footnotetext{
${ }^{3}$ https://github.com/Patent2net/Patent2Net

${ }^{4}$ See http://www.cecill.info/licences/Licence_CeCILL_V2.1-en.html
} 
produced, a patent will be linked to all its bibliographic data attributes, and each of them relied also to the other producing a complete graph for each patent. For instance, the following virtual patent, the network of Erro! Fonte de referência não encontrada. is produced by coupling all bibliographic data as nodes to the patent Node. Notice that for providing several technology analyses (macroscopic to microscopic one), the classification Node is subdivided to its significant part using from one to eleven digits (only 5 in the example below)).

Figure 1. Network nodes of bibliographic data of a single patent corresponding to data beside.
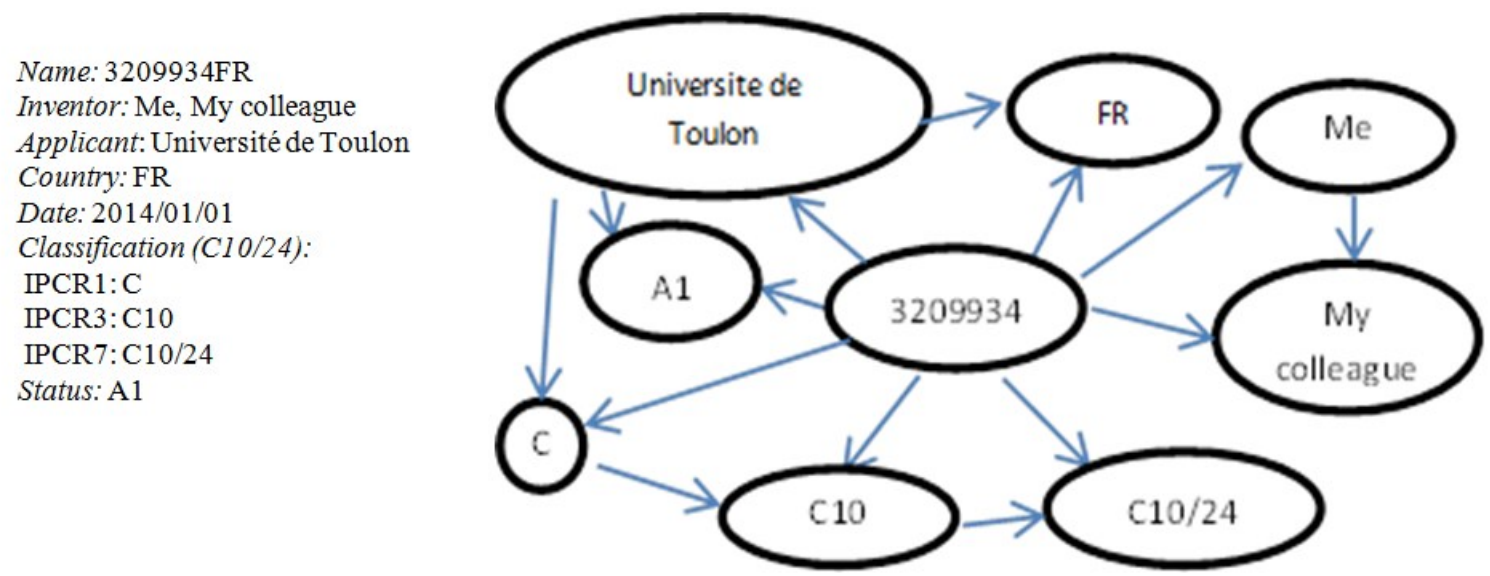

Hence, for a list of patent each bibliographic data will produce a node and the edges for each relationship inherent from the data.

\section{BUILDING PATENTS NETWORKS}

From the precedent, for a list of patent each bibliographic data the PatentToNet tool produces a complete graph for patent data which is inserted to the whole graph for each patent. The complex graph created will be manipulated with Gephi, and will use its ability of filtering, clustering, sub netting, visualizing graphs to explore the several networks.

By analyzing patents with traditional (flat) bibliometrics technic one can address a variety of questions: for example, the impact of social structure on individual creativity [19], knowledge diffusion [45], regional dynamics [8], and 
employment previsions [13]. Some patent analysis software provides yet the use of network representation to explore patent content such as Matheo-Patent ${ }^{5}$ [14] but we give hereafter a more flexible solution that paves the way to new kind of patents analysis.

Hence co-inventors and co-applicant networks which are frequently studied networks are included and will be addressed using the filtering process in Gephi. Furthermore, the network produced presents several knowledge from the gathered patents:

- National technology (IPCR) is focused with the country-classification network, this network relies technologies (IPCR) with countries;

- Inventor and applicant technology (IPCR) assignment with the inventor or applicant classification networks. By analyzing this network one can define who (applicant or inventor) is working with (or is specialist of) what.

Further researches are actually in progress to discuss across network visualization to perceive patents technology in a predefined domain. We present in the suite a study case of application in the competitive intelligence domain dealing with 3D printing.

\section{STUDY CASE: THE DEMOCRATIZATION OF 3D PRINTING}

The 3D printing is a technical of rapid prototyping which is more and more used. Whereas production was only reserved to professionals and industries up to a few years ago, the 3D printing generalization allows everyone to produce 3D structures. In the near future, it is said that people will not be dependent to the manufacturing anymore. So this technology announces an upset in the society especially in production and consumption. However this invention exists for longtime. We claim that it is only its democratization which is new, not its creation. Costs and open source of electronics' 3D printers permitted recently its marketing to the individuals. The application's field of 3D

\footnotetext{
${ }^{5}$ http://www.matheo-software.com/en/products/matheo-patent.html
} 
printing is very wide but the most famous exploits concern low cost prostheses. Even if a revolution is expected, nothing guarantees easy adoption by the public. Today writings often underline the benefits of this invention, as if it had no defects. But words employed to qualify 3D printers are not always rights.

There is a topic that we hear about everywhere and especially in the media, it is the 3D printing. According to the Wohler Report, 23,265 3D printers have been sold in 2011, against 66 in 2007. For the Global Industry Analyst (GIA), this technology will bring $\$ 3$ billion in 2018 [i]. Forbes' report [iv] expects $\$ 3.1$ billion in 2016 and $\$ 5,2$ billions $\$$ en 2020 . So the use of this technology is currently growing.

But what is a 3D printer? It is a traditional printer which adds up material (plastic, metal ...) layer by layer to form a real object in three dimensions. It is controlled by a computer that "reads" a single file containing the model of a 3D object by a 3D scanner. In fact, 3D printing is a technic used for rapid prototyping [3].

So now, with a 3D printer we are able to make small and unique items for all uses: mugs, forks, doorknobs, jewelry, prostheses ... Perhaps in the future we would even build houses, food and organs. This technology announces an upset both in the way of production and in the way of consumption. Some people [xvii][ix][x][v][ii] talk about a "Third Industrial Revolution" and compare the 3D printer with the steam engine [xvi]. Others are neither convinced nor seduces by the use of this machine. But in what sense 3D printer is it a really innovation? We can wonder if this invention will change our society as internet did. Maybe that we expect to do with the 3D printer is utopia. And it is also possible people don't want to use this technology [3] and it may stay for industrial purposes [49]. In the media, only the advantages are shown but there are probably inconvenient, even if nobody talks about it for the moment. No scientific writing relates this subject, it is so difficult to sort the mass of information we have about this invention. 


\subsection{Results from PatentToNet data processing}

By using the patents crawler we obtain 425 patens from OPS. The network built from this bunch of patterns contains 1975 nodes and 45320 links. A first global view in Gephi tool informs us about the complexity of such structure. We use the OpenOrd Spatialization feature such as to extract singularities of this network. Erro! Fonte de referência não encontrada. shows the result. Nodes are colored from their nature (inventor, country, classification, and applicant), length of police is proportional to the frequency of apparition of the node in the dataset. We can observe some patents around a huge set of them.

Figure 2. The complete network using Openord spatialization [36]. This representation shows singularities in the network. Some patent communities are separated from the huge mass of nodes.

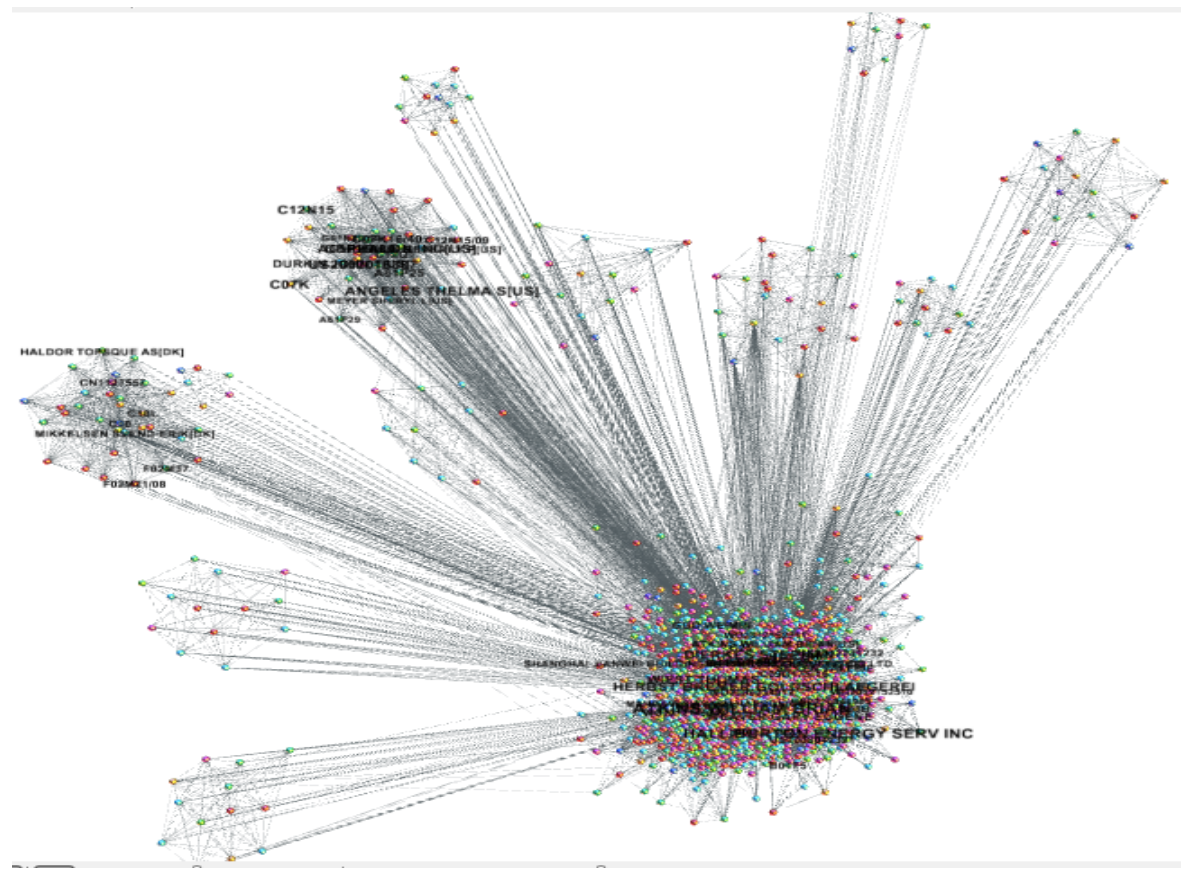

To continue our overall seen of these data, we use as a second process, the time splitting feature. In the laboratory section of Gephi, we first merge for both nodes and links the two columns ('deb' and 'fin') into a time interval. Then timeline splitting is possible. Gephi filtering option allows also segmenting the network showing up only the nodes we want. We choose to seen only the countries, the IPCR level 1, and IPCR level 4. Erro! Fonte de referência não 
encontrada. shows the results for this net. From left to right, we split the data every four year (1998, 2002 and 2006). The last one is the same data as in Erro! Fonte de referência não encontrada. (time is 2014) using only previously cited nodes. These network shows technology dissemination against country in time and a clear gap after 2002 when 7 of the 8 IPCR1 where reached, the full IPC a few years after. The Force Atlas algorithm projects the node to easy understand the technologies and the countries using them.

Figure 3. 3D Print technology dissemination (IPCR1 and IPCR4) against countries from 1996 up to nowadays every four years (from left to right) using Force Atlas 2 spatialization [4].

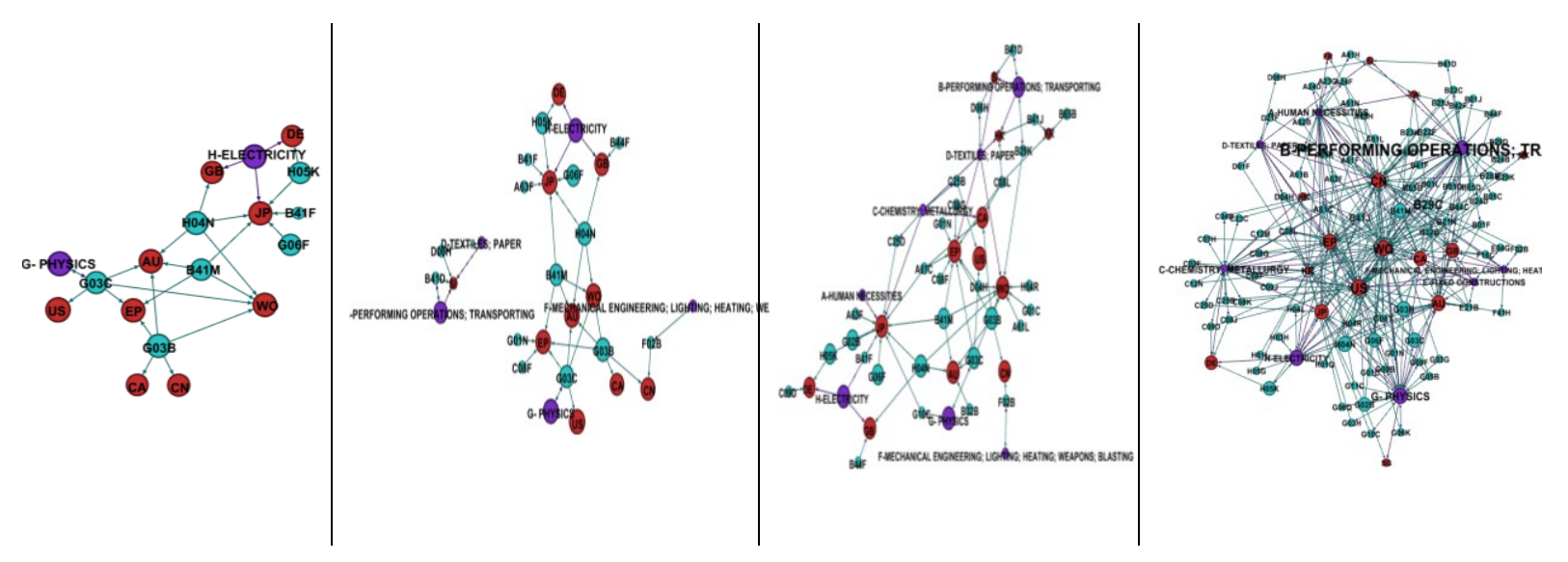

Using the filtering process, we trace the evolution of patent deposits by country and areas. If we move the time line presented on the software we can observe the 3D printing's patents being formed year after year. In Erro! Fonte de referência não encontrada. blue circles represent countries and red circles classifications. Links between circles constitute their relationship. Sizes of circles correspond to patent's volume. Sizes of police are correlated to the date of deposit. Size of police and circles evolve over time. They both grow up when we move the timeline (as patents in the classification and/or in the area were deposited). So, most patents belong to the classification "Performing Operations; transport". This classification contains older patents too. 


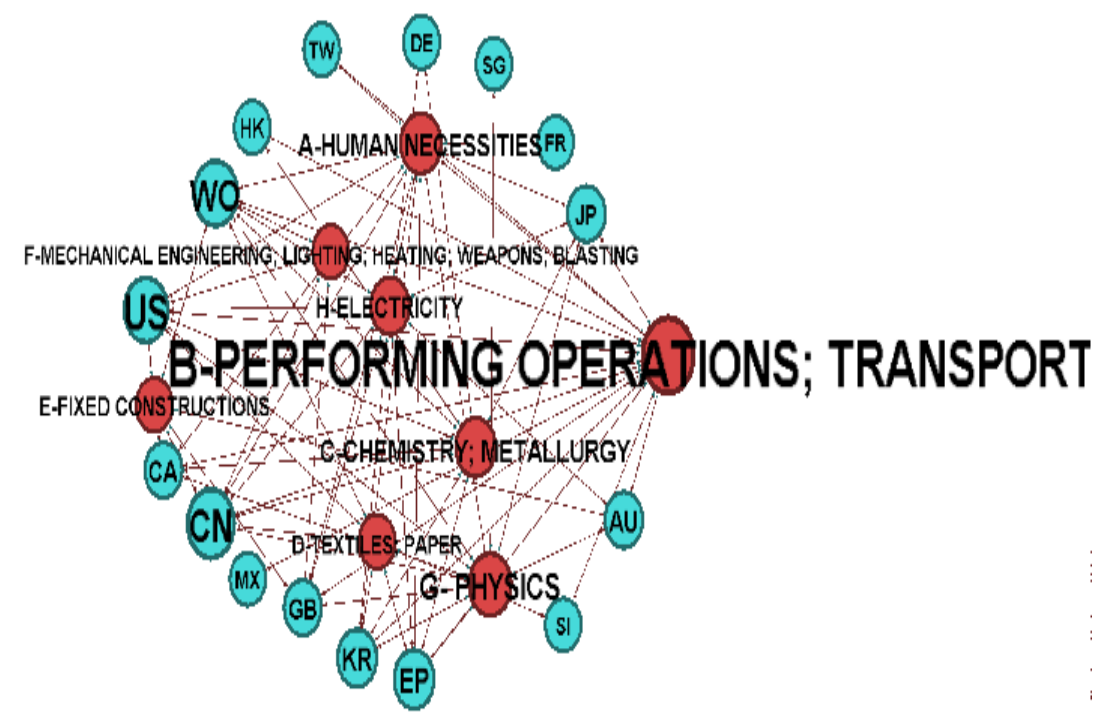

We also note that patents are mainly Chinese, American and worldwide. We can see all other countries who filed a patent treating 3D printers like Canada, France, Taiwan... Patents application for 3D printing are nowadays applied in all fields of the International Patent Classification (IPC).

\subsection{Discussions}

The innovation is (Oslo Manual, [40]) the "implementation -marketing or implantation - by a company, and for the first time, of a product (good or service) or process (production) new or significantly improved, of a new marketing method, or of a new organizational method in business practices, workplace organization or outside relations". Novelty appears as the main criterion to characterize innovation. Oslo manual enhances novelty to define innovation. If we look at the $1^{\text {st }}$ patent deposed or published, we can say 3D printer is not new. According to the definition the 3D printing is not really an innovation since it already existed. From [40], innovation takes 4 forms: product innovation, process innovation, marketing innovation and organizational innovation. 


\subsubsection{Product innovation}

A product innovation is "the introduction of a good or a service, new or significantly improved on characteristics or uses". Improvements of component, materials and software are included [40].We know the ancestor of the 3D printer is the [xi] stereolithography invented by Charles W. Hull who already tough about an additive fabrication. But we also saw the associated technics have changed since: now there are eleven different ways to print in 3D. The success of 3D printing is in its components: they became less expensive and open source. As technics and components evolved in time, the definition shows the 3D printer is a product innovation.

\subsubsection{Process innovation}

The 3D printing also means a process innovation which is "the implementation of a new production's method or a new distribution or sensitively improved" (Oslo). This includes significant changes in technical, equipment and / or software. There are some fields of application where this invention introduced a change in production. Let's take some examples to illustrate this point.

For jewelry, according to [ii] Glenn Lewis, designer and CEO of Distinction Jewelry, it is a great tool to make wax molds to form jewelries. We can create shapes and patterns that would not have been possible to do it by hand. The interest of the 3D printer is to create custom jewelry and especially prototyping to "test" jewelry. One of the world leaders in the field, Dassault Systèmes, created a FashionLab division. [ii] Jérôme Bergeret, director of the FashionLab says his role is to "reconcile technology and craftsmanship ". A jewel created virtually in 3D can be shown to clients, even before the first prototype is built. Rendering these images in 3D is already bluffing because the user can rotate the object in front of his eyes and examine all angles.

In the health domain, two professions are principally concerned. The $1^{\text {st }}$ is the dentist that has to make the molding from the mouths of the patients from 3D scanners. In the United-States, it is permitted to avoid braces in orthodontics for 300,000 patients. The $2^{\text {nd }}$ is the prosthesis, especially for hip prosthesis low 
cost and in best quality. Plasters were also printed in 3D for the Erro! Fonte de referência não encontrada. broken arm of a patient, offering greater comfort with light and airy materials [xiv]. A doctor from the University of Michigan has developed a [xvii] tracheal prosthesis that saved the life of a sick child by preventing the collapse of the trachea and lungs. Also in the United States, a patient has seen $75 \%$ of his skull replaced by a cranial implant produced with this technology. Recently an American invented an artificial low-cost arm, produced by 3D printers, allowing amputees to recover a minimum of autonomy. These prostheses were made for South Sudanese children mutilated in just 6 hours and 75 euros (Daniel project).

Besides, NASA printed in 3D, in just few weeks (instead of 6 months), an injector rocket engine with $70 \%$ efficiency. It is also building a [v] food printer to stock easily food and for longtime (30 years). For example they developed a pizza printer. NASA has a last project which is sending a printer in space. The European Space Agency (ESA), even expects building a lunar base by sending a robot on our satellite. The 3D printer would use the components of the lunar surface as main construction materials to build habitable buildings. It would reduce the cost of bricks' transport needed to build walls.

Finally, searchers at the University of Southern California told that we could build a house of 2500 square feet $\left(230 \mathrm{~m}^{2}\right)$ in 20 hours and at lower costs. It would be a kind of FDM printer but with cement instead of plastic. [iii]The size of the printer is obviously adapted accordingly. The name of these printers, “Contour Crafting 3D”, could even do electrical work, plumbing, tiling, painting and finishing.

\subsubsection{Classical economists}

For [xvi] classical economists, innovation is a way to gain a competitive advantage in meeting the needs of the market and the business strategy. Indeed 3D printers offer the possibility to have competitive advantages for societies. We can produce quickly and mainly produce [xvi]unique objects, custom. For some industries (health, luxury jewelry) we are able to produce on demand 
pieces adapted to the patients or customers. There is the possibility to upset modes of production manufacturing in small series, low cost and with short delivery times. Traditional manufacturing works by subtraction (drilling, cutting and modeling) and about $80 \%$ of the material is rejected. On the contrary, 3D printing works by adding, superimposing fine layers of material. This allows buying less, reducing pieces, and saving fuel when it is transported. Production would be relocated and we would claim for example a status of "Made in France ". Actually manufacturing jobs would be relocated closed to the application and not where they are the least expensive. Finally, we can put an end to the waste generated by consumer society. An article from Forbes explains: "it will no longer make sense to ship raw materials all the way to China to have them assembled into finished products and shipped back to the U.S. Manufacturing will once again become a local industry with products being manufactured near raw materials or markets". When a part of an object is broken, just replace this part and not throw the object completely. Reducing production at a small scale stocks and waste will be minimized. With 3D printing, products will be produced if the client "clicks to buy "as Alice Taylor, founder of MakieLab, a British company producing toys, said. The Economist thinks the SMEs could be interested by the invention". Developing a product in France is expensive. 3D printers could allow companies to innovate at lower cost and gain competitive advantage". It is the passage to a supply-side economics to economy demand.

\subsubsection{Radical or incremental innovation?}

If 3D printer is an innovation, it is more an incremental innovation than a radical. A radical innovation means a total change in organization which is immediate. Or it concerns a new product replacing an obsolete. It signifies a "creative destruction" (Schumpeter). But today 3D printers are not able to substitute other machines and have to be advanced again. The main printed objects are in small size and principally in plastic because other materials like powders' metal are expensive. Furthermore, these objects are not always useful. For example it is always cups, forks, figurines, statues. Besides, before replacing 
anything, the copyright laws need to be adapted to this invention. For example, Joaquin Baldwin had recreated a complete kit of the main characters from Final Fantasy VII. He sold them between \$14 and \$ 60 per unit via Shapeways platform. The company Square Enix, which owns the rights of this game, did remove the goods from the site. Laws have effectively delayed the evolution of technologies. Moreover, Distributed Defense, the association which distributed plans of a plastic gun, had obtained a license to manufacture and sell weapons. The next revolution may well be legislative rather than industrial. Finally, modeling an object is complex and it is difficult to ensure the same reliability of a piece whereas it is not a mature technology, compared to the manufactory used for 200 years. To return to the example of the gun, 3D printing will cause the production of dangerous objects. Thus, according to Mathilde Berchon [6]there are more opportunities for professionals than for individuals.

\subsubsection{Innovation or invention?}

Even if both terms resemble, a nuance exists between this two words. Innovation is built on an invention, but an invention does not give rise to innovation. An innovation is different from an invention or discovery because it fits into an application perspective. Innovate is to introduce something new into use, a custom, belief, scientific or philosophical system. Whereas an invention is primarily a method, a technique, a new means by which it is possible to solve a practical problem given. So, to be an innovation, an invention must be adopted and used by society. Today, 3D printed causes many discussions into the public and it is only used by a minority. So we can consider it is more an invention than an innovation.

\subsection{Debates}

The most fear with the 3D printing is that it becomes a threat for the big manufacturing firms. People will enter in concurrence with the industries. Someone like Benjamin Jean, jurist and founder of Inno Cube, fear the 3D printing might know the same situation than the MP3 which generated a war between internet and cultural industries. According to The Economist, the 
fabricants will use the copyright rather than the patent because the one lasts 70 years after the author's death while the other runes only 20 years. But many people think consumers will have a greater autonomy relative over big industries. We think that it will possible to recycle its own waste plastic to manufacture new items that will make people be more creative. It is what explains an article from the New Times: "3D printing could revamp the economics of manufacturing and revive American industry as creativity and ingenuity replace labor costs as the main concern around a variety of goods". The 3D printer will push some inventors or start-up to launch new products as it will be cheaper and less risky, as The Economist said. The CEO of Alibre, a company permitting to design its products online and send it to users, think: "We will give the opportunity for a class of ordinary people to transform their ideas into real products".

At a TED conference in California, [xii] Mohamed Khoshnevis, Director of the Manufacturing Engineering Graduate program at the University of Southern California explained that a billion people worldwide do not have access to decent housing or are in a situation of poverty, disease, illiteracy, crime and overcrowding. He presents his Contour Crafting process, using 3D printing technology as a solution to solve these problems by creating entire houses. Whereas many people fear the 3D printers might replace workers which would lose their job, Mohamed Khoshnevis believes that Contour Crafting will create new jobs, giving a chance for women and older people to work in new areas of construction. He compares it to the early 1900s when people feared that farming technology ruin the economy by putting unemployed farmers while there are again a lot of farmers in the United States.

If some people denounce the difficulty to use 3D printers, today objects can be modeled and printed with free and quite intuitive software such as Google SketchUp. Moreover, there are workshops called FabLab, like in Barcelona, where 3D printers are accessible to the public in order to repair or create objects and it is a success. A 14-years old boy learned how to use these machines in just 2 days. 
While many specialized revues like the Economist or Wired says the 3D printers will "change the world" once in the hands of public, Alain Bernard, a pioneer of additive manufacturing in France and vice-president of the French Association of rapid prototyping is annoyed by this-worldliness. He refuses to talk about the third industrial revolution, preferring the term sober "evolution." For him, "the revolution is the digital" because without it, the development of these machines would not have been possible. He believes that the adoption of the 3D printer at home will not be easy in a society of immediacy, where the consumer is accustomed to having everything immediately and without effort.

To find their audience, these machines must also meet the requirements of consumers. As noted Alain Bernard, the products designed will have to be equivalent in quality to those found in stores: " It does not take a cup thermally break after two uses." He also stressed that objects created must comply with safety standards in the country. For an individual buys a 3D printer, it must be able to produce enough goods easily equal or better quality than those that are commercially available at a price equal to or lower. Guilhem Peres, co -founder of eMotion Tech, website selling 3D printers, admits that his printers are primarily used to print other 3D print. He says that users often buy these models more for the pleasure of the ride than to manufacture everyday products. His target is "the CSP + who tinker in their garage". In the same idea [vi], Christopher Mims, columnist at MIT review of technology, does not believe the massive and rapid dissemination of 3D printers. It considers talking of revolution "is not only premature, but absurd."

\section{CONCLUSION}

The 80 million deposited patent demands' in the OPS base constitute a huge encyclopedia of technical human knowledge, Thanks to the API it is now possible to consult content at a glance to oversee what have been published in a domain. The amount of data received to a request need to use special way of analyzing and we claimed that network representation and visualization offers a useful way to explore the characteristics of content provided. Further research 
are in progress to state several scenarios in order to exploit network features and characteristics.

About the study case, the possibilities offered by the 3D printing like the personalization are opposed to the Fordist ideology based on the standardization. The 3D could introduce the last form of innovation: organizational innovation. And it is this idea which new. Although the Medias are recently interested by this technology (the additive fabrication), it was invented for thirty years. But it is the recent democratization of this machine that has attracted the interest of technophiles. Actually, in France we can find 3D printers for 400 and 2000 Euros for a machine in good quality, against 11 000 or 17000 Euros six years ago. It is also possible to purchase kit model or print (almost entirely) a 3D printer from another printer. Even if prices are attractive, it will take more than five years to leave the niche market if we believe the "Hype Cycle" of Gartner. Cost, speed and printable materials are the three main factors limiting the mass adoption of 3D printed by consumers. There will probably be a period of deception called "trough of disillusionment" before this technology achieves a "plateau of productivity" and be really used. From the moment a craze was born around a technology, it takes 5 to 10 years for it to become truly accessible technically and financially. According to an article from [vi] Technology Review written by Christopher Mims, is not only "premature", it is also "absurd" to believe the 3D printing will be able to reproduce all objects we use, it is deny "the complexities of modern manufacturing". In his mind, before being in ours houses, 3D printers will be in societies, like 2-D printers or even computer. As a technology is too expensive or requires too much expertise to be massively adopted, it is reserved for a public enlightened amateurs or professionals. Its democratization depends to the specific needs of consumers. It is the reason why professionals are the main users of 3D printers. For example Sculpteo proposes, like a traditional printer, to make objects for others. Even if the 3D printer does not achieve the expected results, according the Business Insider, it will have an impact on the way we buy, sell and produce things. The 3D printer will not permit alone to emancipate market, to relocate production and slow consumer society. But it could occupy 
an important place in a [viii] series of movements (DIY, short circuits, cooperatives ...) that aim to transform the dazed consumer in an informed and responsible citizen. To conclude, talking about revolution and innovation is utopia. The proper term should be democratization. Democratization means an innovation use which is maybe a greater innovation engine than technical innovation. And don't forget thirty years ago, nobody could imagine that we could send images, songs and texts in real time across the world.

\section{ACKNOWLEDGMENT}

We would like to thank Pr. Luc Quoniam who helped us to realize this work.

\section{REFERENCES}

[1] Albornoz, M. (2006), " a RICYT como prctica de trabajo en red », in [2], p. 134-140, chapter 5 .

[2] Albornoz M. and Alfaraz, C. (2014), Redes de conocimiento: construcción, dynámica y gestión, published Red Iberoamericana de Indicadores de Ciencia y Tecnología (RICYT), Buenos Aires, Argentina, august 2005, http://www2.ricyt.org/novedades/74-nueva-publicacion-qredes-deconocimiento-construccion-dinamica-y-gestionq, link followed in Feb.

[3] Bak, David, (2003) "Rapid prototyping or rapid production? 3D printing processes move industry towards the latter", Assembly Automation, Vol. 23 Iss: 4 , pp. $340-345$.

[4] Bastian, M., Heymann, S., and Jacomy, M (2009). Gephi: an open source software for exploring and manipulating networks. In : ICWSM. p. 361-362.

[5] Becker, R. A., Stephen G. Eick, and Allan R. Wilks (1995). "Visualizing Network Data." IEEE Transactions on Visualization and Computer Graphics 1(1): 16-28.

[6] Berchon, M. (2013). L'impression 3D . Eyrolles, 200 p.

[7] Blondel V. D., Jean-Loup, G., Lambiotte R., Lefebvre R., 'Fast unfolding of communities in large networks', Journal of Statistical Mechanics: Theory and Experiment 2008(10), P10008 (12pp) 
[8] Breitkreutz, B.-J., Stark, C. and Tyers, M. (2003). "Osprey: a network visualization system." Genome Biology 4(3): R22. Breschi, S. and Lissoni F. (2009). Mobility of skilled workers and co-invention networks: an anatomy of localized knowledge flows. Journal of Economic Geography 9(4):439-468.

[9] Carayol N., and Cassi L., (2009). Who's Who in Patents. A Bayesian approach. Cahiers du GREThA 2009--07.

[10] Chen, H., Chau, M. and Zeng D. (2002), "CI Spider: a tool for competitive intelligence on the Web." Decision Support Systems vol. 34, n. 1 pp. 1-17.

[11] Díaz, J., Petit, ., and Serna, M. (2002). A survey of graph layout problems. ACM Computing Surveys (CSUR), vol. 34, no 3, p. 313-356.

[12] Degenne, A. et Forsé, M. (1999). Introducing social networks. Sage.

[13] Dou, H., Mohellebi, D., \& Kister, J. (2012, février). , L'importance du traitement bibliométrique des brevets pour développer l'activité industrielle. Exemple des bitumes en Algérie. RIST (Revue Scientifique et Technique), p. vol $19 \mathrm{n}^{\circ} 1$.

[14] Dou, H., Mannina B. et Massari G., (2009)« Análise de patentes para melhorar a competitividdade tecnológica e o pensamento inovador », International Journal of Competitive Intelligence, Strategic, Scientific and Technology Watch (ISSN 2013-0880)

[15] Di Battista, G., P. Eades, R. Tamassia, and I.G. Tollis (1999). Graph Drawing: Algorithms for visualization of graphs,, Prentice Hall.

[16] Eades, P. (1984). "A Heuristic for Graph Drawing." Congressus Numerantium 42: $149-160$.

[17] Eldridge, J. (2006) "Data visualisation tools--a perspective from the pharmaceutical industry." World Patent Information vol. 28, n. 1. pp. 43-49.

[18] Engelsman, E. C. \& van Raan, A. F. J., (January 1994) "A patent-based cartography of technology", Research Policy, Elsevier, vol. 23(1), pages 1-26,.

[19] Fleming, L. and S. Mingo, D. Chen, (2007). Collaborative Brokerage, Generative Creativity, and Creative Success. Administration Science Quarterly, 52: 443-475

[20] Freeman, L. C (2000). Visualizing social networks. Journal of social structure, vol. 1 , no 1, p. 4.

[21] Freeman, L. C. (1979). Centrality in social networks conceptual clarification. Social networks, 1(3), 215-239.

[22] Fruchterman, T. M. and Reingold, E. M. (1991). Graph drawing by forcedirected placement. Softw. Pract. Exper. 21 (11), pp 1129-1164 
[23] Hartigan, J. A. (1975). Clustering algorithms. John Wiley \& Sons, Inc.

[24] Herman, I., Melançon, G. and M. Marshall S. (2000). "Graph Visualization and Navigation in Information Visualization: A Survey." IEEE Transactions on Visualization and Computer Graphics 6 (1): 24-43

[25] Hidalgo-Nuchera, A., Iglesias-Pradas, S. , Hernández-García, Á., (2009) Utilización de las bases de datos de patentes como instrumento de vigilancia tecnológica, El Profesional de la Informacion, Volume 18, Number 5, September - October, pp. $511-520$.

[26] $\mathrm{Hu}, \mathrm{Y}$. «Efficient, high-quality force-directed graph drawing ». Mathematica Journal 10, nº 1 (2005): 37-71.

[27] Huffaker, B., Evi Nemeth, and K. Claffy (1999). "Otter: A general-purpose network visualization tool." Internet Society INET'99 Conference.

[28] Jain, A. K., Murty, Narasimha, M. and Flynn, P. J. "Data clustering: a review". ACM computing surveys (CSUR), 1999, vol. 31, no 3, p. 264-323.

[29] Jain, A. K. and Dubes, R. C. (1988) Algorithms for clustering data. PrenticeHall, Inc..

[30] Kamada, T., and S. Kawai (1989). "An algorithm for drawing general undirected graphs", Information Processing Letters, 31 (1): 7-15.

[31] Kamps, T., J. Kleinz, and J. Read (1995). "Constraint-Based Spring-Model Algorithm for Graph Layout.", Proceedings of Graph Drawing 95 LNCS 1027: 349-360

[32] Lai, R. D'Amour, A. Fleming, L. (2009), "The careers and co-authorship networks of U.S. patent-holders, since 1975", http://hdl.handle.net/1902.1/12367 UNF:5:daJuoNgCZlcYY8RqU+/j2Q== Harvard Business School; Harvard Institute for Quantitative Social Science ,V3

[33] von Landesberger, T., Kuijper, A., Schreck, T., Kohlhammer, J., van Wijk, J.J., Fekete, J.-D. and Fellner, D.W. (2011), Visual Analysis of Large Graphs: Stateof-the-Art and Future Research Challenges. Computer Graphics Forum, 30: 1719-1749. doi: 10.1111/j.1467-8659.2011.01898.x

[34] Liu, S., Liao, H., Pi, S. and Hu, J. (2011). Development of a Patent Retrieval and Analysis Platform - A hybrid approach. Expert Syst. Appl. 38, 6 (June).

[35] Lotka, A. J. (1926). The frequency distribution of scientific productivity. Journal of the Washington Academy of Sciences 16, (12), p. 317-323.

[36] Martin, S., Brown, W. M., Klavans, R., et al. (2011). OpenOrd: an open-source toolbox for large graph layout. In : IS\&T/SPIE Electronic Imaging. International Society for Optics and Photonics.p. 786806-786806-11. 
[37] Masiakowski, P., Wang, S. (2013) "Integration of software tools in patent analysis" - World Patent Information, Volume 35, Issue 2, June 2013, Pages 97-104, Elsevier

[38] Misue, K., Eades, P., Lai, W. and Sugiyama, K. (1995). "Layout Adjustment and the Mental Map." Journal of Visual Languages and Computing 6(2): 183-210.

[39] Moreno, J. L. (1934). Who shall survive? A new approach to the problem of human inter-relations .Washington, DC: Nervous and Mental Disease Publishing Co.Musso, Peirre, Critique des réseaux, Paris, PUF, 2003

[40] OECD (2005), Oslo Manual: Guidelines for Collecting and Interpreting Innovation Data, $3^{\text {rd }}$ edition, 163 pages, PARIS, purl: www.oecd.org/sti/oslomanual

[41] Porter, A. L. et S. W. Cunningham (2005),Tech mining : Exploiting new technologies for competitive advantage. NewYork : Wiley InterScience.

[42] Quoniam, L., Papy F. (ed.) (2013) "Le brevet comme objet de recherche", dans Recherches ouvertes sur le numérique : approches pratiques en information-communication - Paris : Hermès ; Lavoisier, 2013. - 319 p. (Traité des sciences et techniques de l'information, série Environnements et services numériques d'information, ISSN 2104-709X). - ISBN 978-2-74624535-8, p 95-114.

[43] Salampasis M. and Hanbury, A. (2013) "A Generalized Framework for Integrated Professional Search Systems" dans Multidisciplinary Information Retrieval, Lecture Notes in Computer Science, volume 8201, p. 99-100.

[44] Schmookler, J. (1966). Invention and Economic Growth. Cambridge: Harvard University Press

[45] Singh, J. (2003). Social networks as drivers of knowledge diffusion, SSRN.

[46] Spangler, S., Ying, C. , Kreulen, J., Boyer, S., Griffin, T., Alba, A. et al. (2011). "Exploratory analytics on patent data sets using the SIMPLE platform". World Patent Information, $\mathrm{N}^{\circ} 33$, pp. 328-339.

[47] A.J. Trippe, Patinformatics: tasks to tools, World Patent Information, 25 (2003), pp. 211-22.

[48] Tufte, E. R. and Graves-Morris, P. R. (1983). The visual display of quantitative information. Cheshire, CT : Graphics press.

[49] Vinodh, S., Sundararaj, G.,Devadasan, S.R., Kuttalingam, D., Rajanayagam, D., (2009) "Agility through rapid prototyping technology in a manufacturing environment using a 3D printer", Journal of Manufacturing Technology Management, Vol. 20 Iss: 7, pp.1023 - 1041 
[50] Wang, W.M., Cheung, C.F. (2011). "A Semantic-based Intellectual Property Management System (SIPMS) for supporting patent analysis", Engeneering Application and Artificial Intelligence, $\mathrm{N}^{\circ} 24$, pp. 1510-1520.

[51] Wasserman, S., and Faust, K. (1994). Social Network Analysis: Methods and Applications. Cambridge: Cambridge University Press.

[52] Yang, Y., Akers, L., Klose, T. and Yang, C. B. (2008). Text mining and visualization tools - impressions of emerging capabilities, World Patent Information, 30, pp. 280-293.

[53] Young GK, Jong H..S., and Sang C.P. (2008). Visualization of patent analysis for emerging technology. Expert Syst. Appl. 34, 3 (April 2008), 1804-1812.

[54] Mbonguis-Kialo S., "Le brevet, un instrument stratégique au service de l'intelligence informationnelle » in Actes du 5e COLLOQUE SPÉCIALISÉ EN SCIENCES DE L'INFORMATION, «Culture de l'information et pratiques informationnelles durables », Sous la direction de Monica Mallowan, 19-21 juin 2013, UNIVERSITÉ DE MONCTON, CAMPUS DE SHIPPAGA, Canada, p. 107-121

\section{WEB REFERENCES}

[i] "3D Printing Industry Will Reach \$3 Billion by 2018 - Report On 3D Printing". Consulté le 21 janvier 2014. http://on3Dprinting.com/2012/07/23/3D-printing-industry-will-reach3-billion-by-2018-report/

[ii] Bembaron, E. « L'impression 3D , une révolution ». Le Figaro. Consulté le 8 décembre

2013.

http://www.lefigaro.fr/conjoncture/2013/11/23/20002-

20131123ARTFIG00227-l-impression-3D -une-revolution.php.

[iii] Berry, P. « Où en est la révolution de l'impression 3D ? » 20minutes.fr. $\begin{array}{lllll}\text { Consulté } & \text { le } & 8 & \text { décembre } & 2013 .\end{array}$ http://www.20minutes.fr/sciences/1098963-ou-vraiment-revolutionimpression-3D.

[iv] McCue, T]. « 3D Printing Industry Will Reach \$3.1 Billion Worldwide by $2016 »$. Forbes. Consulté le 21 janvier 2014. http://www.forbes.com/sites/tjmccue/2012/03/27/3D -printingindustry-will-reach-3-1-billion-worldwide-by-2016/.

[v] Gummich, Swen. « Les Imprimantes 3D : une révolution? | ARTE Future ». arte TV. Consulté le 8 décembre 2013. http://future.arte.tv/fr/sujet/les-imprimantes-3D 
[vi] Hubert Guillaud, «L'impression 3D est-elle le moteur de la fabrication de demain ?», Internet Actu, http://www.internetactu.net/2012/02/08/limpression-3d-est-elle-lemoteur-de-la-fabrication-de-demain/

[vii] IPO, 2013, «3D printing a patent overview», Report from the UK Intellectual Property Office Patent Informatics Team, November 2013

[viii] «Ethics, Health and Death 2.0: the low-Cost But High-Voltage Innovation Blog: L'imprimante 3D , "machine à vapeur du XXIème siècle" ? " LowCost Innovation. Consulté le 21 janvier 2014.

http://ethictransplantation.blogspot.fr/2012/12/limprimante-3D machine-vapeur-du-xxieme.html.

[ix] «Impression 3D : "la révolution a déjà commencé" ». France Info. Consulté le 8 décembre 2013. http://www.franceinfo.fr/high-tech/lesnouveaux-mondes-de-l-innovation/impression-3D -la-revolution-a-dejacommence-1181601-2013-10-20.

[x] «L'impression 3D : la révolution arrive dans le grand public ». Sciences et Avenir. Consulté le 8 décembre 2013. http://www.sciencesetavenir.fr/imprimante-3D /20131118.0BS5825/limpression-3D -la-revolution-arrive-dans-le-grand-public.html.

[xi] Mathieu, F. « Histoire de l'impression 3D ». MonUnivers3D . Consulté le 26 janvier 2014. http://www.monunivers3D .com/guide/histoire/.

[xii] Neal, R. W. « Gimme Shelter: 3D Printing The New Housing Industry? » International Business Times, 29 octobre 2013. http://www.ibtimes.com/3D -printers-build-entire-houses-contourcraftings-aims-print-2500-square-foot-homes-20-hours-video.

[xiii] OFFICE EUROPEEN DES BREVETS: Open Patent Services (OPS) [en ligne: http://www.epo.org/searching/free/ops.html] - consulté le 13/01/2014. Organisation mondiale de la propriété intellectuelle, OMPI http://www.wipo.int/patentscope/fr/ consulté le 14/01/14.

[xiv] Peek, Devin, and Stark, E. (2010). Three Dimensional Printing: Modern Medical Applications, Graphic Communication Department, College of Liberal Arts, California Polytechnic State University , 38 p.

[xv] « Print me a Stradivarius ». The Economist, février 2011. http://www.economist.com/node/18114327.

[xvi] Untersinger, M. (2013) « Révolution: l'imprimante 3D, la machine à vapeur du XXIe siècle? " Rue89. Consulté le 8 décembre. http://www.rue89.com/2012/10/17/revolution-limprimante-3D -lamachine-vapeur-du-xxie-siecle-236194. 
[xvii] Venne, J.F. (2013). «Impression 3D : pour quand la révolution?». Agence Science - Presse. Consulté le 8 décembre. http://www.sciencepresse.qc.ca/actualite/2013/09/03/impression-3Dpour-quand-revolution.

Stinson, L. (2014) «Is This 3D Printed Cast the Future of Healing Broken Bones?

| Wired Design | Wired.com ». Wired Design. Consulté le 21 janvier 2014.

http://www.wired.com/design/2013/07/is-this-cast-the-future-of-healing- 